\title{
The 'timely' development of Rexin-G: First targeted injectable gene vector (Review)
}

\author{
ERLINDA M. GORDON and FREDERICK L. HALL \\ Epeius Biotechnologies Corporation, 475 Huntington Drive, San Marino, CA 91108, USA
}

Received May 20, 2009; Accepted June 9, 2009

DOI: 10.3892/ijo_00000332

\begin{abstract}
In an age where we can i) know precisely where a misplaced automobile resides by its global positioning, ii) send mechanistic probes to Mars with pinpoint accuracy, iii) calculate exactly how many mutations are required to create (i.e., to transform) a cancer cell, and iv) determine how many fewer genes it takes to develop a human being than it does a rice plant, it is difficult to fathom the previously unanswered question: 'Whatever happened to the promise and potential of cancer gene therapy?' This review answers that question with a resounding clinical dénouement. In addition, it provides a 'Cooks tour' of applied molecular genetics and nanotechnology as these fields relate to the development of Rexin-G the world's first tumor-targeted genetic medicine to be fully validated in the clinic. The commentary will expose certain fallacies and ideologies that have retarded the progress of cancer gene therapy as it advances our instruments and understanding of the finespun fabric of our nature.
\end{abstract}

\section{Contents}

1. Introduction

2. Nature's very own nanotechnology

3. Caution! A modern medicine should not be a replicating species

4. The advent of pathotropic targeting

5. Molecular pathways and strategies of cellular growth control

6. The natural history of Rexin-G

7. Clinical development in extremis

8. The heart and the lonely hunter

9. Time is of the essence

Correspondence to: Dr Erlinda M. Gordon, 475 Huntington Drive, San Marino, CA 91108, USA

E-mail: egordon@epeiusbiotech.com

Key words: cancer therapy, gene therapy, gene vector, targeted genetic medicine, molecular genetics, molecular targeting, tumortargeting, pathotropic medicine

\section{Introduction}

This biomedical review is timely, not only in terms of our chronological time in history, or 'chronos', but in terms of 'kairos' -that is, the qualitative time of a significant momentthat crucial time when an opening appears which must be driven through with significant force if success is to be achieved. The time at which targeted genetic medicine no longer stands poised at the threshold of history, but forcefully crosses that very threshold for the benefit of countless cancer patients who have previously languished on the chain of failed expectations, should be considered 'kairosis time' in this epic journey of scientific discovery. The clinical development of Rexin-G, the world's first tumor targeted genetic medicine that actually seeks out and destroys metastatic cancer from the inside, represents the culmination of the unflagging efforts of many generations of physicians and scientists who have sought out the molecular genetic basis of disease to its rock bottoms, laying the foundations of physiology, biochemistry, genetics and microbiology, establishing the transformative industries of biotechnology and nanotechnology, and heralding the 'kairosis time' when the molecular genetic basis of pathology could be translated into the safer and more-effective medicines of the future. This timely review will focus on the conceptual basis, the scientific foundations and the recent clinical development of Rexin-G-the world's first and, so far, only broad-spectrum, tumor-targeted, bio-compatible, systemically-injectable genetic medicine for cancer, which actually 'works' in the clinic (1), precisely as it was designed to do (Fig. 1). The review assumes a posture of the medical avant-garde, but does not assume that the reader is either a molecular, genetic, or biotechnological cognoscente. The subject matter addressed herein is necessarily focused on very recent developments in the field, while pertinent background material on applied nanotechnology $(2,3)$, gene delivery vehicles (4-6), cell cycle control $(7,8)$, virotherapy $(9,10)$ and tumor targeting technologies (11-15), as well as early clinical trials of Rexin-G (16-18) and associated histopathology (19) are available in the existing literature. The text is divided into discrete subsections in which critical distinctions are made and considered opinions are presented, in a strategic flow of contextual information that travels from the theoretical to the clinical to the analytical and beyond, to the evolving praxis of modern medicine. 

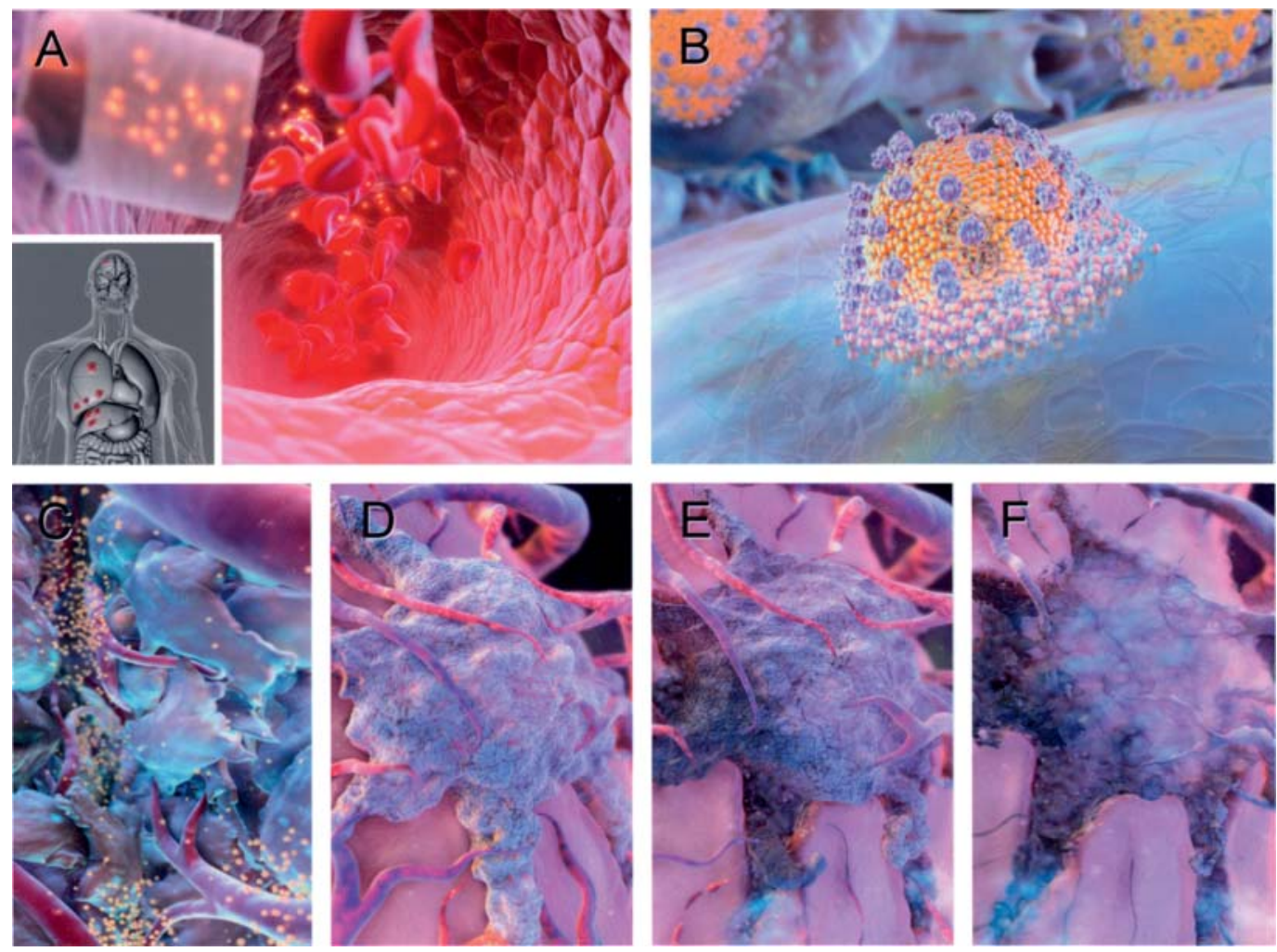

Figure 1. Targeted genetic medicine comes of age. Rexin-G, the world's first-targeted, injectable gene vector to be validated in the clinic, is administered by simple intravenous infusion (A). Distributed by the systemic circulation, the tumor-targeted nanoparticles seek out the biochemical hallmarks of tumor histopathology $(11,12)$ and accumulate selectively in metastatic lesions that have spread throughout the body (see insert). Conceptually, Rexin-G is a small but complex gene delivery vehicle (3), which is based on the structural engineering of the retroviral core but is devoid of viral genes-carrying instead, a lethal form of the human cyclin-G1 gene as its molecular 'payload'. Upon membrane fusion (B) and entry of a Rexin-G nanoparticle into a proliferative target cell (i.e., cancer cells and tumor vascular cells), the cyto-ablative designer gene is delivered. Integration and expression of this therapeutic 'transgene', in the target cells produces numerous copies of the cytocidal gene product which disrupts cell cycle progression and induces apoptosis (cell death). Rexin-G nanoparticles accumulate in tumorous tissues to high levels (C) causing massive cell degeneration and necrosis of both cancer cells and associated vasculature (D) and (E), leading to gradual tumor destruction $(\mathrm{F})$.

\section{Nature's very own nanotechnology}

'To engineer the primal elements of nature into a medicine for the future, it is practical to employ the language and mechanisms of creation' (3); and it is this engineering practicality that brings us to the lowly viral particle who, lacking other corporeal properties, has become exceedingly adept at the art of gene delivery in vivo. The fact that viral nanoparticles are capable of overcoming all of the much talked about in vivo barriers to gene delivery $(20,21)$, combined with the painstaking molecular deconstruction, and hence removal, of all of the infectious (potentially replicative) viral elements from the core gene delivery apparatus, has yielded a lifeless therapeutic gene delivery vehicle (or vector) that is capable of delivering a given therapeutic gene once, and only once, in vivo, while eliminating concerns of wild-type viral replication and viral infectivity (see section 3 ). The challenge remaining is to strategically align the set of virtues and limitations inherent in each 'replication incompetent' vector system with the particular therapeutic goal in mind.

In the case of intractable cancer, where repeated applications of a given therapy are required, and immunological reactivity toward the vector are contraindicated, the retroviral core gene delivery apparatus has a number of virtues and limitations that are favorably aligned. Generated from human producer cells, the lipid envelope-cloaked nanoparticles $(\sim 100 \mathrm{~nm})$ are virtually invisible to the patient's immune system and are neither inflammation-provoking nor immediately inactivated by the immune system, thereby allowing for repeated intravenous infusions without untoward sideeffects. The restriction of therapeutic gene delivery to proliferative cells (i.e., mitotically active cancer cells and their proliferative neo-vasculature) further enhances the safety and selectivity, in terms of non-target organs. The delivery of cytocidal genetic constructs that effectively destroy the target tumor cells and/or their associated blood supply eliminates the major problems associated with insertional mutagenesis and engraftment of genetically altered cells, which has plagued gene therapy applications in the past. The singular limitation of retroviral vectors that previously stymied the clinical development of these otherwise ideal gene delivery vehicles was the inability to effectively target these stealth nanoparticles under physiological conditions (22-24), a precondition that remained daunting until the advent of pathotropic targeting (11-19) (also see section 4).

\section{Caution! A modern medicine should not be a replicating species}

At this point, a categorical distinction -indeed, a moral distinction- must be made between the replication incompetent retroviral vector (presented herein), which is constructed from 
inert components with no replication competent characteristics and the infectious species of viruses that has been advocated in recent years $(9,10,25-27)$ with a disturbing epidemiological naiveté and a less than convincing scientific rationale. It appears that the same cadre of experts that had all previously tried and failed to develop a clinically useful gene delivery vector based on the preferable retroviral core (28-33), have collectively agreed that the only means of delivering sufficient genes in vivo is to use infectious variants of the viral life forms themselves (34-39). While this irrational exuberance does succeed in eliminating the necessity of manufacturing sufficient quantities of clinical-grade vectors under GMP conditions (see section 8), the idea of unleashing known pathogenic organisms, even attenuated variants thereof, in a weakened, often immune-compromised population obviates the most basic of medical principles with unmitigated, unconscionable abandon, that is, primum non nocere.

This point is of such grave concern that it should be made historically and indelibly clear: 'Declare the past, diagnose the present, foretell the future; practice these acts. As to diseases, make a habit of two things - to help, or at least to do no harm.' (Hippocrates, Epidemics, Bk I, Section XI). First, do no harm to the patient, to those who come in contact with the patient, to the human genome and to humanity itself. With a working knowledge of the natural mutability of all microorganisms, including infectious viruses, the knowledge that this natural mutability is capable of engendering even more virulent subspecies $(40,41)$, even from attenuated vaccines (e.g., polio, HIV), and the realization that the entire field of organ xenotransplantation was virtually banned by the potentiality that transmissible pathogenic viruses could be incubated within the bodies of immuno-compromised hosts, this decadent reversion to such medically dubious notions arises more from the collective frustrations of the failed and ineffectual apothecaries than from solid scientific principles and medical thinking. Hence, it bears reiterating that Rexin-G is the first and only systemically injectable, immunologically stealth, mechanistically defined, genetically stable, certifiably replication incompetent gene delivery vehicle that is designed and proven to be safe and effective in the clinic.

\section{The advent of pathotropic targeting}

The development of the pathotropic (or disease-seeking) targeting embodied in Rexin-G (11-19) (reviewed in refs. 3 and 18) stemmed from a basic understanding of physiology and biophysics, as applied to a critical problem of molecular engineering. Long before the human genome project was initiated, long before the term functional genomics was introduced into the medical literature, Doctor Erik von Willebrand (1926) described a rare form of pseudo-hemophilia in which the unfortunate patients exhibited a complete coagulation cascade and a normal number of platelets, but would die from uncontrollable bleeding at a young age. It was subsequently determined that the patients and their platelets were missing a vital factor (named von Willebrand factor, vWF) and that this large and mechanistically complex protein (42-44) essentially attaches to and guides the otherwise 'blind' platelet to the site of vascular injuries wherein the platelets function to initiate the clotting process while laying down several powerful growth factors (i.e., PDGF, IGF-1 and TGF- 3 ) at the precise locus of the injury. Once the physiological surveillance function of vWF was sufficiently understood and then deconstructed into minimalistic domains, the remaining challenge for the biophysicist/would-be bioengineer (F.L.Hall) was to re-establish this structural wound-seeking moiety onto the envelope of another structurally durable, widely-circulating, potentially therapeutic, but relatively blind and very much smaller medicinal unit; that is, without disturbing the intricate receptor-mediated cell recognition, membrane fusion and cell entry mechanisms that account, in part, for the overall efficiency of the retroviral vector system. The design engineering was ultimately successful.

Without belaboring or diminishing the ingenuity and outright inventiveness involved in the elaboration and testing of the molecular targeting technologies embodied in the structure and function of Rexin-G, it should suffice to note, in retrospect, that one only needed to be as smart as a platelet with an eye on the fabric of nature itself. You see, the very fabric which nature selected as the basis of this applied engineering (aka pathotropic targeting) are the substratum of collagenous proteins that are freshly and characteristically exposed at the site of a significant injury. Apparently, nature abhors exposed collagens, as much as it does a vacuum, and that is the crux of the matter. Indeed, modern oncologists are beginning to shift their focus from the aberrant cancer cell to the supportive tumor stroma in their pursuit of strategic anticancer targets $(45,46)$. When, in time, the essential concepts of pathotropic targeting are fully grasped (intellectually) and the extreme penetrance of the retroviral nanoparticle is fully appreciated (practically), the potential clinical applications for cardiovascular medicine, ischemia, infarct, stroke, infections, inflammation, and wound healing applications, in addition to metastatic cancer, will extend beyond the reach of the most gifted surgeons, beyond the diameter of the finest of catheters, to the foundations of disease itself, as collagen patefacio (exposure) are added to the classical hallmarks: rubor (redness), calor (heat), tumor (swelling) and dolor (pain).

\section{Molecular pathways and strategies of cellular growth control}

Of the three critical components of the tumor-targeted retroviral vector, we have covered two: the structural core and gene expression cassette, which has been developed to the point that it represents a new state of the art (47), and the targeting technology that involved genetic re-engineering of the surface or envelope protein to provide a physiological gain-of-function (12). The third critical component in Rexin-G involves the therapeutic payload that must be up to the task of destroying cancer with broad spectrum bioactivity. The ability of Rexin-G, by itself, to exhibit such broad spectrum anticancer activity (i.e., all solid tumors) when each and every other biological agent is largely ineffective as monotherapy and is thereby given in combination with other anticancer agents to attain a semblance of clinical statistical significance is, once again, by design. By understanding the fundamental designs of complex biochemical pathways and building upon what we learned from balloon injured arteries, we soon realized that blockade of receptor mediated events at the 


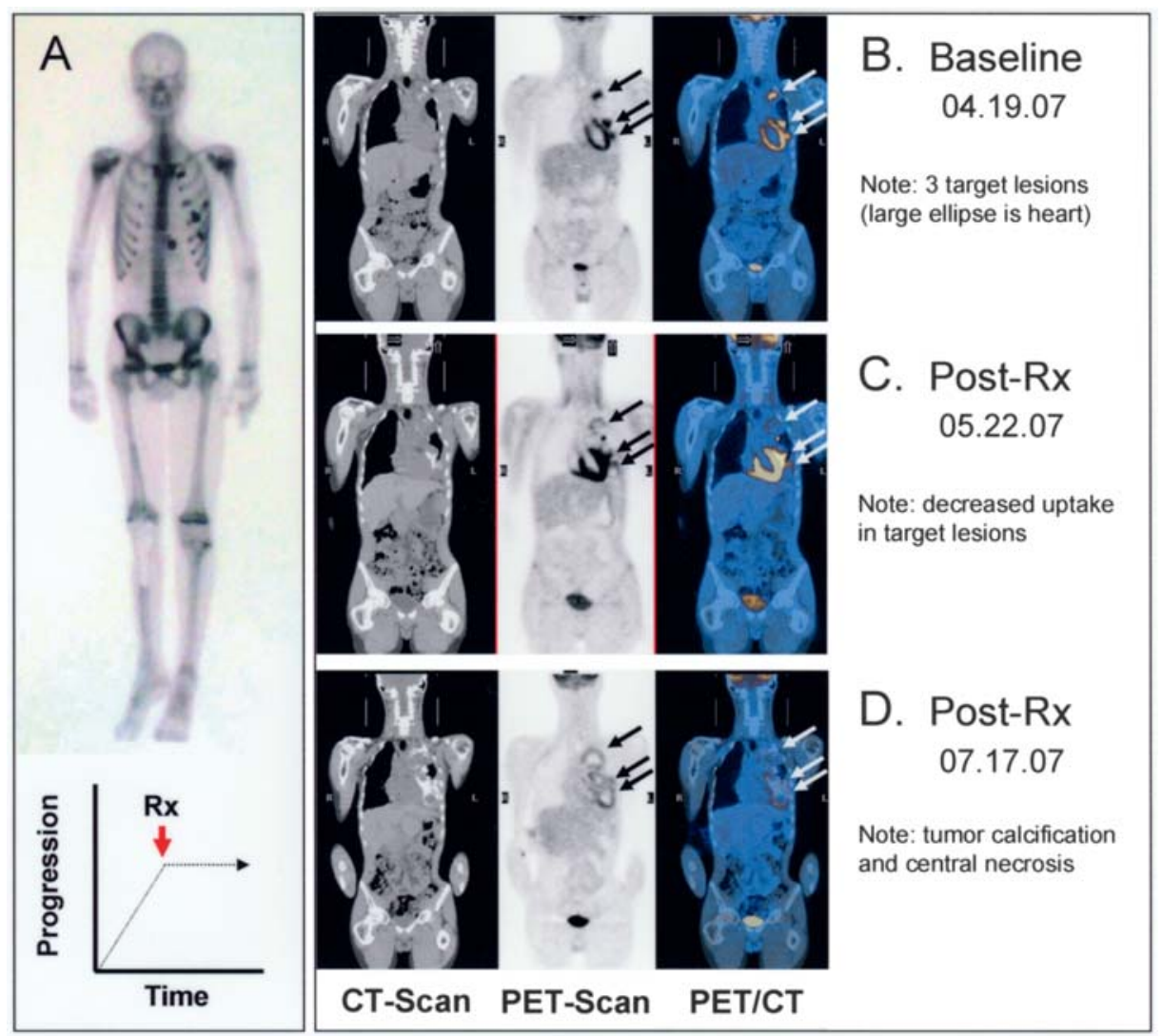

Figure 2. Halting the progression of chemo-resistant osteosarcoma. Following limb salvage surgery (right leg), radiation and multiple chemotherapies, the recurring bone cancer in this young patient had spread to the lung, the vessels surrounding the heart and the adrenal gland (A), with multiple new lesions appearing at an increasing rate (graph). Baseline readings of both standard CT-scans and tumor metabolism-sensing PET-scans (B) identified several critical 'target lesions', which were dramatically altered by each treatment with Rexin-G administered as monotherapy (C) and (D). The alarming location of these target lesions attests to the nearly 'surgical' precision of the tumor-targeting and the specificity of the anti-cancer activity. In osteosarcoma, the extent of necrosis and calcification in tumors (not RECIST criteria) are considered to be indicative of therapeutic efficacy.

surface of the cell was woefully ineffectual, and even the vaunted field of signal transduction offered little in the way of furtherance (48-50). If all attempts to block the benign hyperplasia of vascular restenosis (normal smooth muscle cell proliferation) based on impairing signal transduction pathways had failed, the same approaches were bound to fail when confronted with the increased adaptability and progressive variability of cancers.

In brief, for Rexin- $G$ to gain broad spectrum bioactivity, it took an appreciation of the common final pathways of cellular growth control, which are conserved from yeast, to frog eggs, to man, to focus our attention on the executive enzymes and those determinate mechanisms at the base of the cell cycle which control the stages of cell growth and death and are governed by the cyclin-dependent $(51,52)$ proline-directed (53) protein kinases. As in all classical biochemical pathways, the regulatory leverage is arrayed up front, at the headwaters of the enzymatic cascades; and it is here at the mysterious boundaries of 'cell competence' which normal cells occasionally cross during the process of cell activation and cancer cells have permanently crossed in the process of neoplastic transformation that cyclin G1 is suspected to act. Induced during cell injury $(54,55)$, activation and/or transformation $(56,57)$, operating at the convergence of oncogenesis and tumor suppression (58-61), intimately involved in the mechanisms of DNA fidelity invoked during cell cycle progression
$(62,63)$, the enforced expression of cyclin G1 advances the cell cycle (64), while its blockade is invariably lethal (13$16,48,65)$, particularly to cancer cells, derived from all three germ layers.

It merits mentioning that initial antisense constructs (suppressive designs) were replaced early-on with a dominant negative construct in the final embodiment of Rexin-G, that effectively sabotages said biochemical pathways in a veritable sea of normal cyclin $\mathrm{G}$ protein, which offers a distinct advantage in terms of preventing a target cell from overcoming the lethal blockade with over-expression or biochemical redundancy. With the growing number of potentially oncogenic mutations being ascribed to the aberrant function and expression of protein kinases, whose enzymatic turnover numbers are measured in milliseconds and whose cellular expression and function are often regulated by feedback inhibition, this 'word to the wise' relates to the wholly suppressive field of iRNA as well.

In the age of ambitious genetic profiling, where we are continually finding that the onset and progression of cancer is associated with an ever-increasing number of genetic mutations (66-68), even within a single cancer patient (69), and that the mutations involving signal transduction pathways may well obviate the therapeutic benefit of biological agents that ostensibly block classical receptor-mediated pathways $(70,71)$, it might lead one to conclude that the importance of moni- 

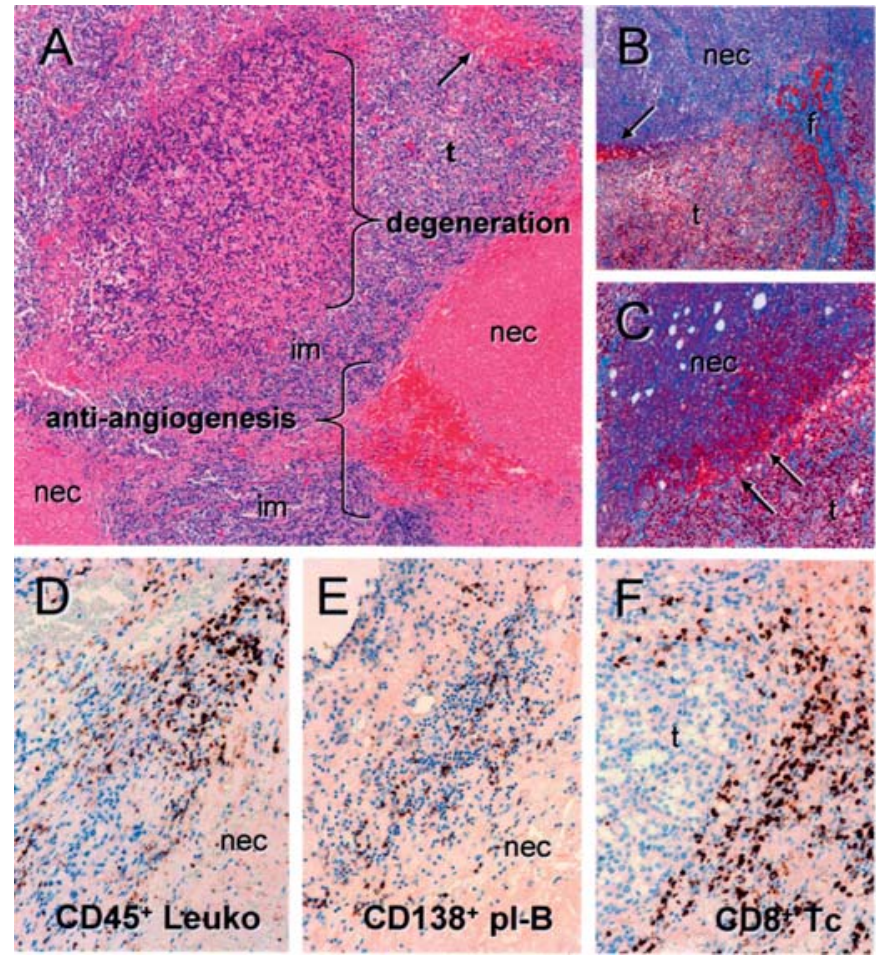

Figure 3. Tumor destruction viewed at the microscopic level. In this case of recurrent chemo-refractory leiomyosarcoma, an opportune surgical biopsy following repeated i.v. administrations of Rexin-G (as monotherapy), the classical characteristics of tumor destruction under the onslaught of precision-targeted genetic medicine can be seen (A), significant yet discrete areas of anti-angiogenesis are evident, along with large areas of focal cell degeneration, zones of complete necrosis (nec) and significant amounts of reactive immune infiltrate (im) into the tumor (t). Histological trichrome staining for tumor extracellular matrix proteins (B) and (C) provides a targeted nanoparticle's 'view' of these histological processes (collagens stain blue). Among the numerous immune cells (leukocytes) recruited into the dying tumor (D), presumably by the abundance of neo-antigens and debris, there are an appreciable number of antibody-producing plasma B-cells (E) and killer T-cells $(\mathrm{F})$, which are a highly favorable prognostic indicator.

toring the increasing multitude of problematic profiles that might define the subset of the subset of cancers, that might just respond to the 'superficial' treatment (72), that is, for a short while. In the case of pancreatic cancer, blocking either the popularized VEGF or EGF receptor-mediated pathways ultimately failed to provide any survival value for the patient (73). In fact, 'the frustrating lack of significant clinical advancements in the treatment of metastatic pancreatic cancer remains one of medical oncology's biggest disappointments' (74). Moreover, blocking generalized receptor-mediated pathways, like 'housekeeping' metabolic pathways (e.g., $\mathrm{PKC}$, the much-touted phorbol ester receptor), cannot be considered innocuous, nor can serious side-effects encountered in recent clinical trials be considered surprising (75-77). Such considerations might lead one to reconsider the profound clinical utility, if not the insightful biologic, of an anticancer agent that offers precision delivery and broad spectrum anticancer activity, by design.

\section{The natural history of Rexin-G}

Finally, in 2001 the therapeutic payload (a cytocidal mutant of cyclin G) was 'packaged' into a retroviral core and assembled, along with its newfound physiological guidance system, into a clinical grade vector known as Rexin-G $(16,78,79)$. Far from a euphonious pharmaceutical appellation gleaned from favorable marketing surveys, Rexin-G is simply a convenient laboratory acronym (Retroviral expression Vector bearing an inhibitory construct of the gene-cyclin $\mathbf{G}$ ), thus reflecting its molecular engineering roots. Following extensive preclinical studies of gene delivery, safety, efficacy and biodistribution, Rexin-G was first deployed against Stage IV pancreatic cancer in the Philippines under approved Compassionate Use protocols in a remarkable example of international cooperation. The innovative protocols utilized intrapatient dose escalations of intravenous Rexin-G (based on preclinical studies), which carefully monitored safety parameters before proceeding to the next higher doses (16-18). The promising results of these initial Compassionate Use studies, which soon thereafter extended to the United States, were sufficient in terms of documented safety and efficacy (as well as the lack of available treatments for this chemotherapy-resistant cancer) for the U.S. FDA to grant Orphan Drug Status in 2003.

Supported, in part, by the U.S. FDA-Office of Orphan Product Development (OOPD), a standard Phase I safety study for stage IV chemo-resistant pancreatic cancer was initiated at the Mayo Clinic, which provided the lower steps of a slow and gradual inter-patient dose escalation protocol, which simply confirmed the overall safety of repeated infusions of Rexin-G, with no dose-limiting toxicity (80). The progressive dose escalations of Rexin- $G$ into the ranges needed to 'meet and match' the progression of this deadly form of cancer proceeded rapidly in the Sarcoma Oncology Center, Santa Monica, USA, in a series of three Phase I/II trials, for advanced chemotherapy-resistant i) pancreatic cancer, ii) breast cancer, and iii) sarcoma, respectively, using adaptive trial designs $(81,82)$. Remarkably, the concerted and comprehensive interim analyses enabled the FDA to approve an across-the-board dose escalation, once overall safety was clearly established. Stemming from the impressive results of the Phase I/II sarcoma studies (Fig. 2), a Phase II confirmatory trial specifically for chemotherapy-resistant osteosarcoma was initiated (83).

Meanwhile, clinical development in the Philippines outpaced the U.S. trials in expanding the clinical applications to include breast cancer, colon cancer, lung cancer, laryngeal cancer, malignant melanoma (17), revealing definitive histological hallmarks of tumor destruction $(18,19)$, demonstrating the potential of a combined Rexin-G/Reximmune-C vaccination protocol $(47,84)$, leading to an expanded access program for solid tumors and ultimately to accelerated approval of Rexin-G as a safe and effective anticancer agent for all solid tumors in December, 2007. Importantly, the mechanisms of tumor destruction under the onslaught of Rexin-G, including cellular apoptosis, degeneration and necrosis, as well as focal anti-angiogenesis, were revealed in exquisite detail (Fig. 3). Expansion of a pilot Compassionate Use Program in Japan added efficacy in glioblastoma, gall bladder cancer, gastric cancer and lung cancer. Orphan Drug status was granted by the U.S. FDA for osteosarcoma and for soft tissue sarcomas in the summer of 2008. Based on these unprecedented demonstrations of single-agent efficacy, in the context of previously intractable cancers, Epeius Biotechnologies was granted two 

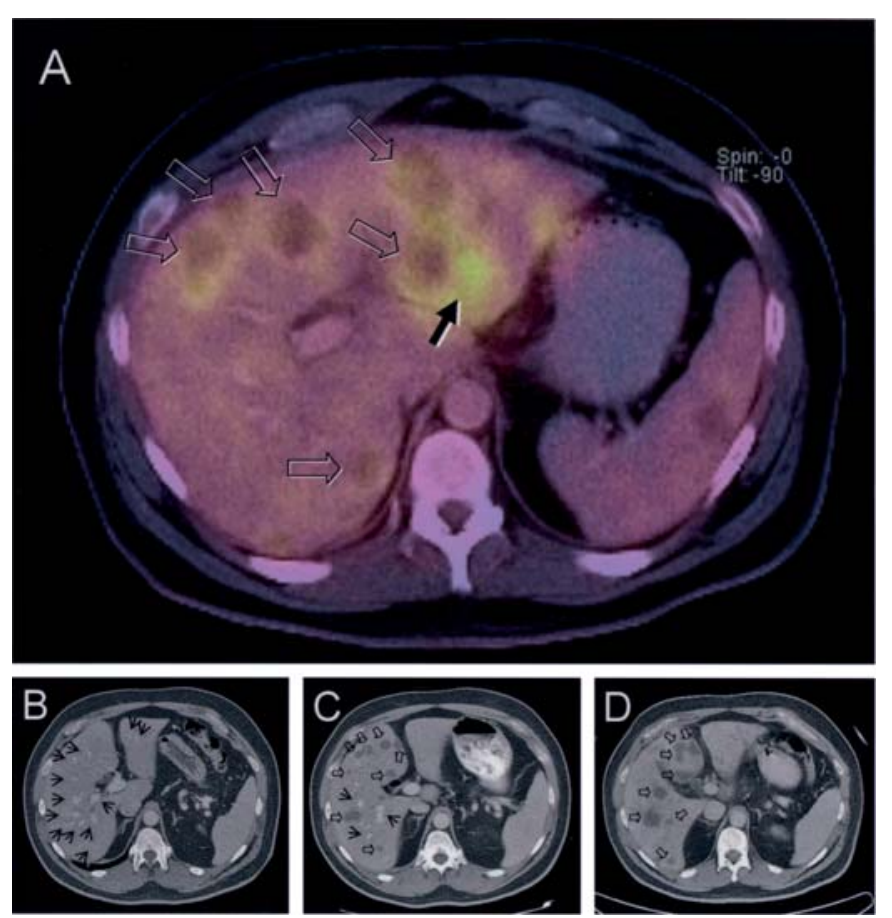

Figure 4. Tumor eradication in the face of end-stage disease. This decidedly terminal case of pancreatic cancer approaches 'organ replacement' of the liver with flagrant tumors deemed 'too many to count'. Repeated infusions of Rexin-G, by itself, induced significant necrosis of the majority of the liver nodules, as evinced by the dark centers (hollow arrows) versus the bright center (solid arrow) of the nodules revealed by the PET scan (A). Following the patient from the initial presentation (B) where numerous solid tumors are noted throughout the liver (simple arrows), through courses of Rexin-G where partial or mixed responses are marked by hollow arrows (C), to the point where the vast majority of the flagrant tumors have been reduced in radiological density (hollow arrows), signifying focal necrosis. End-stage cases such as this, where unprecedented single-agent efficacy is clearly evident and Rexin-G is proven to be sufficiently mild for hospice care, the challenge to convert such terminal cancer to a consistently survivable disease remains and will require a major re-orientation in patient care from dismissingly hospice to appropriately supportive during the subsequent stages of wound-healing and organ regeneration.

major patents, in the USA and Europe $(85,86)$, for bringing forth the world's first targeted genetic medicine that was proven to function systemically; that is, in the human circulatory system in vivo.

\section{Clinical development in extremis}

At this point in chronological time, patient enrollment in the sarcoma and osteosarcoma trials have been completed, and the initial reports have been released into the medical literature (81-83). The bottom line, for the purposes of this review, is that both the genetic payload and tumor-targeting technology embodied in Rexin-G are profound, enabling unprecedented 'reach' and significant therapeutic benefit in the context of otherwise intractable metastatic disease (Fig. 4). In each case, including pancreatic cancer, soft tissue sarcoma and osteosarcoma, Rexin-G exhibits dose-dependent efficacy with no dose limiting toxicity or other safety concerns, while reductions in tumor burden and rate of progression, without major side-effects, reflects directly on overall quality of life. In both sarcoma and osteosarcoma, and again in pancreatic cancer, overall survival and progression-free survival are extended, which represents a gold standard, by any measure, and encourages further analysis, where there once was incredulity. In pancreatic cancer in particular, the painfully slow inter-patient dose escalations conducted at the Mayo Clinic, Rochester, USA, eventually led to predictable dose-response curves and the establishment of practical 'thresholds' for significant biological activity and improvements in survival in clinical studies conducted in Santa Monica, USA (81-83).

The importance of these progressive dose-escalation studies, which clearly establish safety, before escalating to more potent tumoricidal levels, is of primary concern in the development of a new genetic medicine like Rexin-G. Moreover, the establishment of a functional dose-response relationship is also of fundamental significance, not only in terms of basic pharmacology, but in establishing the physiological mechanisms of action that are of major importance in determining the predictability of a new anti-cancer agent, in establishing the optimal dose regimens for a given type of cancer, and ultimately in gaining regulatory approval for Rexin-G in the United States, and elsewhere. The true value of these pioneering studies and the enlightened intentions of the physicians, scientists and regulators who made these medical advances possible, lies not only in the development of a superior medicine for end-stage cancer where all else has failed, but in the verifiable proofs of principle that metastatic cancer is no longer beyond the reach of the physician. The resolve to treat one individual patient, one intractable disease at a time, is not for the faint of heart, but the intended purpose of this arduous journey is near at hand. At this pivotal time in history (i.e., 'kairosis time'), the technological means to reduce the mortal threat of metastatic cancer to that of a survivable disease may be well within our grasp (Fig. 5).

A remarkable clinical finding, which may be considered anecdotal at this point but is important to note nonetheless, is that Rexin-G appears to act with such precision as to solve clinical problems rather than cause issues resulting in systemic distress. Unlike conventional chemotherapies, which can cause significant damage to internal organs, immune suppression, abnormal blood chemistries and deleterious changes in liver and kidney function, Rexin-G has been associated with profound improvements in liver function, ascites, blood chemistries, diabetes subsequent to pancreatic adenocarcinoma, wound healing, and a curious decrease in withering pain that is often associated with metastatic cancer. As the emergent concept of collagen patefacio (exposed collagen) is added to the classic hallmarks of inflammation, including tumor (swelling) and dolor (pain), a greater understanding of the molecular mechanisms by which these dutiful disease-seeking nanoparticles 'act' at the very forefront of cancer metastasis can be gained.

\section{The heart and the lonely hunter}

Administered by simple intravenous infusion, Rexin-G circuits the heart, the lungs and the heart again to be distributed widely by the circulatory system, while it seeks out and accumulates selectively in cancerous tissues and delivers a killing gene to the cancer cells and their associated neovasculature. Indeed, Rexin-G is clearly capable of 'halting the 

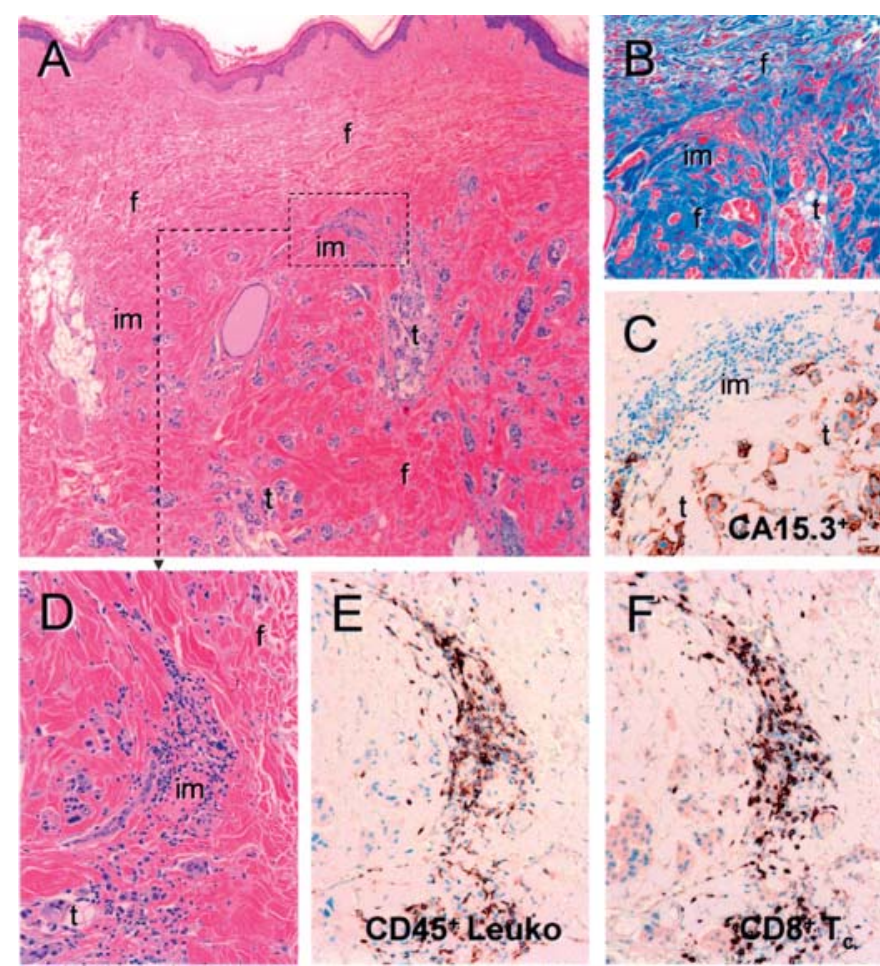

Figure 5. Rexin-G enables a potentially curative surgical resection. In this case of metastatic, chemo-resistant breast cancer, repeated infusions of Rexin-G effectively eradicated several metastatic tumor nodules and reduced the remaining 'target lesion' to that of a small $(6 \mathrm{~mm})$ operable nodule that was then surgically excised and embedded for histological analysis (A). Far from a flagrant tumor, the small residual nodule was found to be largely fibrotic (f), as confirmed by trichrome stain (B) for extracellular matrix proteins (blue). Immunohistochemical staining for a specific tumor marker $(\mathrm{C})$ revealed scant nests and remnants of tumor cells $(\mathrm{t})$ as well as significant immune infiltrate (im) into the residual lesion. Further characterization of the immune infiltrate seen in Plate A (D) and (E), revealed a large number of killer T-cells $(\mathrm{F})$, which may have been beneficial, as this patient enjoyed a long-term remission and is still alive $>1 \frac{1}{2}$ years after receiving Rexin-G followed by surgical-resection.

progression' of metastatic disease and of eradicating tumors from such vulnerable organs as the liver and lung. Yet, however capable the tumor-targeting system and however lethal the designer gene, there is a critical amount of vector needed to produce the mass-action of tumor destruction that leads to accomplishment of objective clinical responses (Figs. 3-5). By quantifying the amounts of Rexin-G that are needed to 'meet and match' the progression and spread of a given type of end-stage cancer, a 'Calculus of Parity' was developed $(17,18)$ which adds a predictive pharmacological component in terms of calculating the approximate cumulative doses of vector needed for a given patient's tumor-burden. In addition to defining the biologic thresholds and parities needed for Rexin-G monotherapy to achieve a significant level of tumor control, it is anticipated that additional mathematical formulations will be forthcoming to further define the optimal induction and maintenance protocols, as well as optimal dosing for Rexin-G when used in combination and/or adjuvant settings.

These quantitative pharmacological considerations point directly to the need to manufacture more of a small good thing under stringent bio-manufacturing conditions. Accordingly,

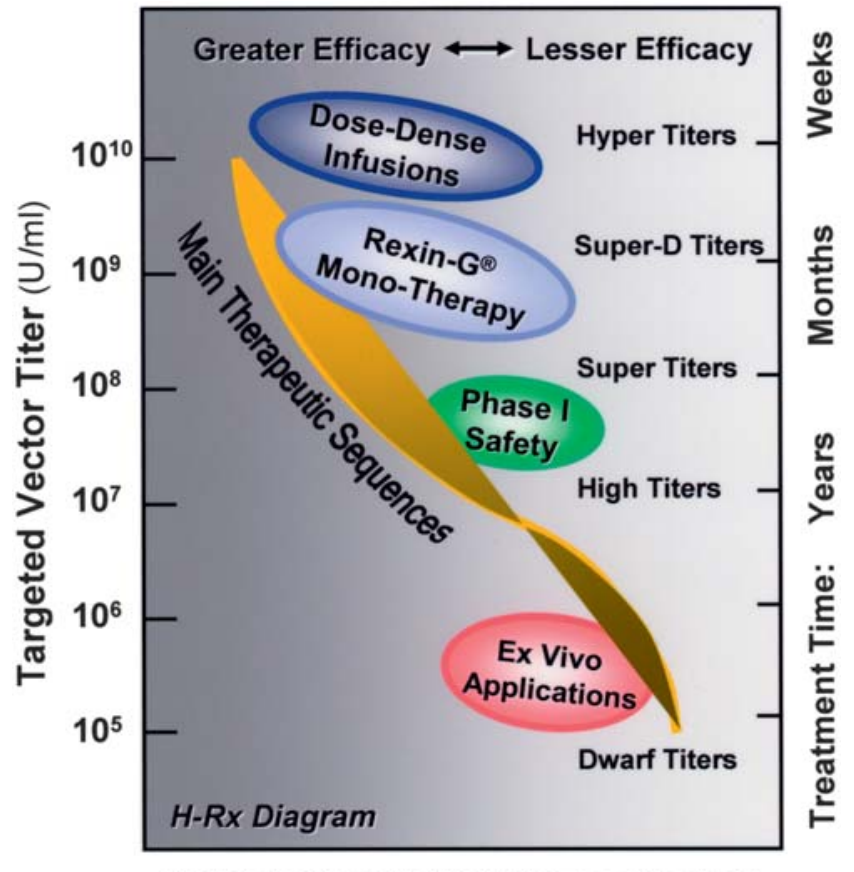

$1 /$ Biological Activity (Tumor Control)

Figure 6. Far-reaching perspectives on targeted genetic medicine. The effective titers of available clinical-grade vectors are plotted along with the inverse of biological activity and the prospective time-courses of advanced clinical treatment protocols. The parallel of this human gene therapy (H-Rx) diagram with the astrophysicist's Hertzsprung-Russell (or H-R) diagram, which reveals the relationship between the magnitude, luminosity and duration of stars, is purposeful, as it encourages the viewer to think of tumor-targeted cancer gene therapy in terms of clinical mass action. From the dwarf titers $\left(<10^{6}\right)$ that are suitable merely for ex vivo (laboratory) applications with little clinical impact, to the high titers $\left(10^{7}\right)$ of the Phase I safety studies, to the super-high titers $\left(10^{8}-10^{9}\right)$ where Rexin-G exhibits dose-dependent efficacy as mono-therapy and the 'thresholds' of biological activity have been established for several tumor types. With the availability of vector hyper-titers $\left(>10^{10}\right)$ in the foreseeable future, it is conceivable that strategic induction/maintenance protocols may indeed shorten the time of intensive clinical intervention from months to weeks.

the rapid development and deployment of Rexin-G in clinical trials has necessitated the reformulation of product potency from $10^{7}$ nanoparticles per milliliter (used in safety studies) to more than one hundred-fold, to that of $10^{9}$ nanoparticles per milliliter now used today. Considering this GMP advancement in terms of the clinic: weekly doses that were once administered in multiple i.v. bags slowly over a period of hours each day, at a rate limited by patient volume tolerances, is now exceeded by a simple 5-10 minute 'push' administered three times per week. Moreover, continued research in biomanufacturing and bio-processing development presages the availability of hyper-titers, that is, titers beyond $10^{10}$ nanoparticles per milliliter, which may enable the clinical development strategic of dose-dense regimens in the future (Fig. 6).

\section{Time is of the essence}

The timely clinical development of Rexin-G has served to validate the potential of pathotropic targeting as a new and important platform for technologically-advanced medical delivery vehicles, of which Rexin-G serves as the flagship. 
The ability for such targeted genetic medicine to seek out and accumulate selectively in diseased tissues such as metastatic cancer, and to deliver an anti-cancer agent precisely to where it is needed most, has opened a new chapter in the annals of medical praxis. With these first voyages of Rexin-G, the general safety and the first critical thresholds for biological responses have been established, as well as the fundamental dose-response relationships upon which future protocols will be based. As Rexin-G continues to demonstrate profound single agent efficacy where all previous medications and all other biologics have uniformly failed, the potentiality for additional targeted therapeutics, and combinations of such therapeutics, becomes apparent, as does the practicality of using Rexin-G as both neoadjuvant and adjuvant therapy with surgical resections (Fig. 5).

The demonstrated capability of Rexin-G to halt the progression of metastatic cancer and to extend survival, even in the most terminal stages, bodes well for continued innovation in pathotropic medicine. The vast number of prospective clinical applications now appears to be as numerous as the evening stars, obscured only by the prevailing weather and the fog rising from the caldrons of the ineffectual apothecaries. Indeed, a biophysicist may consider the clinical development of Rexin-G as a physicist views a Hertzsprung-Russell diagram, in which all stars are arrayed in accordance with their theoretical mass, brilliance and duration of action (Fig. 6). Viewed from the lofty perspective of an intentional allegory, that is, emphasizing the fundamental importance of mass action, one can see that it is the effective local titer of a given genetic medicine that both governs and predicts the therapeutic potential. From the meager titers used in standard in vitro applications through the titers used in the safety trials to the super-high titers where Rexin-G exhibits efficacy as monotherapy, it is now conceivable that the achievement of even greater titers (i.e., hyper-titers) may serve to provide dosedense regiments that not only increase the efficacy, but shorten the time-course of treatments needed to positively impact survival. In conclusion, it bears mentioning that each and every one of the clinical benefits achieved at the terminal edge of end-stage cancer can be magnified exponentially when pathotropically-targeted agents like Rexin-G are allowed to (and ultimately mandated to) be given earlier in the course of a malignant disease - for, after all, that is how cancer grows within us - exponentially.

\section{Acknowledgements}

The authors are grateful to Dr Sant P. Chawla, for his contributions as principal investigator of the Phase I/II and Phase II studies of Rexin-G in Santa Monica CA, to Dr Gerardo C. Cornelio, Dr Conrado C. Lorenzo III, Dr Francisco F. Lopez, for their contributions as investigators of the clinical studies conducted in the Philippines, to Dr Howard W. Bruckner, of Bruckner Oncology Center, New York, Dr Herbert Zeh, of University of Pittsburgh, PA, and Dr John Kavanaugh, of UT M.D. Anderson Cancer Center, Houston TX, for their compassionate use studies, to Dr Takaki Imamura, Japan, for his clinical contributions in the use of Rexin-G for glioblastoma, gall bladder cancer, gastric cancer and lung cancer, and to Dr William Blackwelder, of the University of Maryland for statistical analysis of clinical data. The authors are also grateful to John P. Levy, Rebecca A. Reed, W. Nina Petchpud, Liqiong Liu for their scientific contributions, to Victoria S. Chua, Lita Fernandez, Antonette Balais, Evangeline Camunayan, Alicia B. de Guzman, Rose Marie Cavanna Mast, Peter Mast and Jun de Guzman for clinical trials coordination, study monitoring and data management.

\section{References}

1. Waehler R, Russel SJ and Curiel DT: Engineering targeted viral vectors for gene therapy. Nat Rev Genet 8: 573-587, 2007.

2. Zhang Y and Chatterjee DK: Liposomes, Dendrimers and other Polymeric Nanoparticles for targeted delivery of anticancer agents - a comparative study. In: Nanomaterials for Cancer Therapy. Chalia S and Kumar SR (eds). Wiley-VCH Verlag GmbH \& Company, KGaA, Weinheim, pp338-370, 2006.

3. Gordon EM and Hall FL: Nanotechnology blooms, at last (Review). Oncol Rep 13: 1003-1007, 2005

4. Dingli D and Russell SJ: Genetic targeting of retroviral vectors. In: Vector Targeting for Therapeutic Gene Delivery. Curiel DT and Douglas JT (eds). John Wiley \& Sons, Inc., New Jersey, pp267-291, 2002.

5. Noureddini SC and Curiel DT: Genetic targeting strategies for adenovirus. Mol Pharm 2: 341-347, 2005.

6. Schaffer DV, Koerber JT and Lim KI: Molecular engineering of viral gene delivery vehicles. Annu Rev Biomed Eng 10: 169-194, 2008.

7. Viallard JF, Lacombe F, Belloc F, Pellegrin JL and Reiffers J: Molecular mechanisms controlling the cell cycle: fundamental aspects and implications for oncology. Cancer Radiother 5: 109-129, 2001.

8. Csikasz-Nagy A, Novak B and Tyson JJ: Reverse engineering models of cell cycle regulation. Adv Exp Med Biol 641: 88-97, 2008.

9. Davis JJ and Fang B: Oncolytic virotherapy for cancer treatment: challenges and solutions. J Gene Med 7: 1380-1389, 2005.

10. Vile R, Ando D and Kirn D: The oncolytic virotherapy treatment platform for cancer: Unique biological and biosafety points to consider. Cancer Gene Ther 9: 1062-1067, 2002.

11. Gordon EM, Hall FL, Beart RW Jr and Anderson WF: Genetic engineering of targeted retroviral vectors. In: Vector Targeting for Therapeutic Gene Delivery. Curiel DT and Douglas JT (eds). Wiley-Liss, Inc., New Jersey, pp293-320, 2002.

12. Hall FL, Liu L, Zhu NL, Stapfer M, Anderson WF, Beart RW and Gordon EM: Molecular engineering of matrix-targeted retroviral vectors incorporating a surveillance function inherent in von Willebrand factor. Hum Gene Ther 11: 983-993, 2000.

13. Gordon EM, Liu PX, Zhen SH, Liu L, Whitley MD, Gee C, Groshen S, Hinton DR, Beart RW and Hall FL: Inhibition of metastatic tumor growth in nude mice by portal vein infusions of matrix-targeted retroviral vectors bearing a cytocidal cyclin G1 construct. Cancer Res 60: 3343-3347, 2000.

14. Gordon EM, Liu PX, Chen ZH, Liu L, Whitley MD, Liu L, Wei D, Groshen S, Hinton DR, Beart RW, Anderson WF and Hall FL: Systemic administration of a matrix-targeted retroviral vector is efficacious for cancer gene therapy in mice. Hum Gene Ther 12: 193-204, 2001.

15. Chen DS, Zhu NL, Hung G, Skotzko MJ, Hinton D, Tolo V, Hall FL, Anderson WF and Gordon EM: Retroviral vectormediated transfer of an antisense cyclin G1 construct inhibits osteosarcoma tumor growth in nude mice. Hum Gene Ther 8: 1679-1686, 1997.

16. Gordon EM, Cornelio GH, Lorenzo CC, Levy JP, Reed RA, Liu L and Hall FL: First clinical experience using a 'pathotropic' injectable retroviral vector (Rexin-G) as intervention for Stage IV pancreatic cancer. Int J Oncol 24: 177-185, 2004.

17. Gordon EM, Lopez FF, Cornelio GH, Lorenzo CC III, Levy JP, Reed RA, Liu L, Bruckner HW and Hall FL: Pathotropic nanoparticles for cancer gene therapy. Rexin-GTM: Three-year clinical experience. Int J Oncol 29: 1053-1064, 2006.

18. Gordon EM and Hall FL: A primer on pathotropic medicine. In: Celebrating One Hundred Years of the Food and Drug Administration. A Special Centennial Edition. Brooklands New Media Ltd, Oswestry, pp80-83, 2007. 
19. Gordon EM, Chan MT, Geraldino N, Lopez FF, Cornelio GH, Lorenzo CC III, Levy JP, Reed RA, Liu L and Hall FL: Le morte du tumour: Histological features of tumor destruction in chemo-resistant cancers following intravenous infusions of pathotropic nanoparticles bearing therapeutic genes. Int J Oncol 30: 1297-1307, 2007

20. Chen HH, Cawood R and Seymour LW: Toward more effective gene delivery. Genome Biol 9: 1-301, 2008.

21. Brower V: Cancer gene therapy steadily advances. J Natl Cancer Inst 100: 1276-1278, 2008.

22. Hendrie PC and Russell DW: Gene targeting with viral vectors. Mol Ther 12: 9-17, 2005.

23. Witlox MA, Lamfers ML, Wuisman PI, Curiel DT and Siegal GP Evolving gene therapy approaches for osteosarcoma using vira vectors (Review). Bone 40: 797-812, 2007.

24. Ryu BY, Zavorotinskaya T, Trentin B and Albritton LM: The block to membrane fusion differs with the site of ligand insertion in modified retroviral envelope proteins. J Gen Virol 89: 1049-1058, 2008.

25. Prestwich RJ, Harrington KJ, Pandha HS, Vile RG, Melcher AA and Errington F: Oncolytic viruses: a novel form of immunotherapy. Expert Rev Anticancer Ther 8: 1581-1588, 2008

26. Liu T and Kirn D: Systemic efficacy with oncolytic virus therapeutics: clinical proof-of-concept and future directions. Cancer Res 67: 429-432, 2007.

27. Thorne SH: Oncolytic vaccinia virus: from bedside to benchtop and back. Curr Opin Mol Ther 10: 387-392, 2008

28. Lavillette D, Russell SJ and Cosset FL: Retargeting gene delivery using surface-engineered retroviral vector particles Curr Opin Biotechnol 12: 461-466, 2001.

29. Sandrin V, Russell SJ and Cosset FL: Targeting retroviral and lentiviral vectors. Curr Top Microbiol Immunol 281: 137-178, 2003.

30. Kasahara N, Dozy AM and Kan YW: Tissue-specific targeting of retroviral vectors through ligand-receptor interactions. Science 266: 1373-1376, 1994

31. Han X, Kasahara N and Kan YW: Ligand-directed retroviral targeting of human breast cancer cells. Proc Natl Acad Sci USA 92: 9747-9751, 1995.

32. Kan O, Griffiths L, Baban D, Iqball S, Uden M, Spearman H, Slingsby J, Price T, Esapa M, Kingsman S, Kingsman A, Slade A and Naylor S: Direct retroviral delivery of human cytochrome P450 2B6 for gene-directed enzyme prodrug therapy of cancer. Cancer Gene Ther 8: 473-482, 2001.

33. Braybrooks JP, Slade A, Deplanque G, Harrop R, Madhusudan S, Forster MD, Gibson R, Makris A, Talbot DC, Steiner J, White L, Kan O, Naylor W, Carroll MW, Kingsman SM and Harris AL: Phase I study of MetXia-P450 gene therapy and oral cyclophosphamide for patients with advanced breast cancer or melanoma. Clin Cancer Res 11: 1512-1520, 2005.

34. Blechacz B and Russell SJ: Measles virus as an oncolytic vector platform. Curr Gene Ther 8: 162-175, 2008.

35. Allen C, Paraskevakou G, Liu C, Iankov ID, Msaouel P, Zollman P, Myers R, Peng KW, Russell SJ and Galanis E: Oncolytic measles virus strains in the treatment of gliomas. Expert Opin Biol Ther 8: 213-320, 2008

36. Dalba C, Bellier B, Kasahara N and Klatzmann D: Replicationcompetent vectors and empty virus-like particles: new retroviral vector designs for cancer gene therapy or vaccines. Mol Ther 15: 457-466, 2007.

37. Tai CK and Kasahara N: Replication-competent retrovirus vectors for cancer gene therapy. Front Biosci 13: 3083-3095, 2008

38. Harrop R, Drury N, Shingler W, Chikoti P, Redchenko I, Carroll MW, Kingsman SM, Naylor S, Melcher A, Nicholis J, Wassan H, Habib N and Anthoney A: Vaccination of colorectal cancer patients with modified vaccinia ankara encoding the tumor antigen 5T4 (Trovax) given alongside chemotherapy induces potent immune responses. Clin Cancer Res 13: 4487-4494, 2007.

39. Harrop R, Drury N, Shingler W, Chikoti P, Redchenko I, Carroll MW, Kingsman SM, Naylor S, Griffiths R, Steven N and Hawkins RE: Vaccination of colorectal cancer patients with Trovax alongside chemotherapy (5-fluorouracil, leukovorin and irinotecan) is safe and induces potent immune responses. Cancer Immunol Immunother 57: 977-986, 2008.

40. Valsamakis A, Auwaerter PG, Rima BK, Kaneshima H and Griffin DE: Altered virulence of vaccine strains of measles virus after prolonged replication in human tissue. J Virol 73: 8791-8797, 1999.
41. Berkhout B, Verhoef K, van Wamel JLB and Back NKT: Genetic instability of live, attenuated human immunodeficiency virus type 1 vaccine strains. J Virol 73: 1138-1145, 1999.

42. Fressinaud E, Mazurier C and Meyer D: Molecular genetics of type 2 von Willebrand disease. Int J Hematol 75: 9-18, 2002.

43. Sugimoto M and Miyata S: Functional property of von Willebrand factor under flowing blood. Int J Hematol 75: 19-24, 2002.

44. Andrews BK and Berndt MC: Platelet physiology and thrombosis. Thromb Res 114: 447-453, 2004.

45. Taylor RA and Risbridger GP: Prostatic tumor stroma: a key player in cancer progression. Curr Cancer Drug Targets 8: 490-497, 2008.

46. Ahmed F, Steele JC, Herbert JM, Steven NM and Bicknell R: Tumor stroma as a target in cancer. Curr Cancer Drug Targets 8: 447-453, 2008.

47. Gordon EM, Levy JP, Reed RA, Petchpud WN, Liu L, Wendler CB and Hall FL: Targeting metastatic cancer from the inside: a new generation of targeted gene delivery vectors enables personalized cancer vaccination in situ. Int J Oncol 33: 665-675, 2008.

48. Gordon EM, Zhu NL, Prescott MF, Chen ZH, Anderson WH and Hall FL: Lesion-targeted injectable vectors for vascular restenosis. Hum Gene Ther 12: 1277-1287, 2001.

49. Xu F, Prescott MF, Liu PX. Chen ZH, Liau G, Gordon EM and Hall FL: Long term inhibition of neointima formation in balloon-injured rat arteries by intraluminal instillation of a matrix-targeted retroviral vector bearing a cytocidal mutant cyclin G1 construct. Int J Mol Med 8: 19-30, 2001

50. Braun-Dullaeus RC, Mann MJ and Dzau VJ: Cell cycle progression: new therapeutic target for vascular proliferative disease. Circulation 98: 82-89, 1998.

51. Santamaria D and Ortega S: Cyclins and CDKs in development and cancer: lessons from genetically modified mice. Front Biosci 11: 1164-1188, 2006.

52. McDonald ER 3rd and El-Deiry WS: Cell cycle control as a basis for cancer drug development (Review). Int J Oncol 16: 871-886, 2000

53. Hall FL and Vulliet PR: Proline-directed protein phosphorylation and cell cycle regulation. Curr Opin Cell Biol 3: 176-184, 1991.

54. Morita N, Kiryu S and Kiyama H: p53-independent cyclin G expression in a group of mature neurons and its enhanced expression during nerve regeneration. J Neurosci 16: 5961-5966, 1996.

55. Maeda M, Ampo K, Kiryu-Seo S, Konish H, Ohba N, Kadono C and Kiyama $\mathrm{H}$ : The p53-independent nuclear translocation of cyclin G1 in degenerating neurons by ischemic and traumatic insults. Exp Neurol 193: 350-360, 2005.

56. Seo HR, Lee DH, Lee HJ, Baek M, Bae S, Soh JW, Lee SJ, Kim J and Lee YS: Cyclin G1 overcomes radiation-induced G2 arrest and increases cell death through transcriptional activation of cyclin G1. Cell Death Differ 13: 1475-1484, 2006.

57. Perez R, Wu N, Klipfel AA and Beart RW Jr: A better cell cycle target for gene therapy for colorectabl cancer: cyclin G. J Gastrointest Surg 7: 884-889, 2003.

58. Reimer CL, Borras AM, Kurdistani SK, Garreau JR, Chung M, Aaronson SA and Lee SW: Altered regulation of cyclin G in human breast cancer and its specific localization at replication foci in response to DNA damage in p53+/+ cells. J Biol Chem 274: 11022-11029, 1999

59. Baek WK, Kim D, Jung N, Yi YW, Kim JM, Cha SD, Bae I and Cho $\mathrm{CH}$ : Increased expression of cyclin G1 in leiomyoma compared with normal myometrium. Am J Obstet Gynecol 188: 634-639, 2003.

60. Jensen MR, Factor VM, Fantozzi A, Helin K, Huh CG and Thorgeirsson SS: Reduced hepatic tumor incidence in cyclin G1-deficient mice. Hepatology 37: 862-870, 2003

61. Zhao L, Samuels T, Winckler S, Korgaonkar C, Tompkins V, Horne MC and Quelle DE: Cyclin G1 has growth inhibitory activity linked to the ARF-Mdm2-p53 and pRb tumor suppressor pathways. Mol Cancer Res 1: 195-206, 2003.

62. Ohtsuka T, Ryu H, Minamishima YA, Ryo A and Lee SW: Modulation of p53 and p73 levels by Cyclin G: implications of a negative feedback regulation. Oncogene 22: 1678-1688, 2003.

63. Kimura SH, Ikawa M, Ito A, Okabe M and Nojima H: Cyclin $\mathrm{G} 1$ is involved in $\mathrm{G} 1 / \mathrm{M}$ arrest in response to DNA damage and in growth control after damage recovery. Oncogene 20: 3290-3300, 2001

64. Smith ML, Knotny HU, Bortnick R and Fornace AJ Jr: The p53-regulated cyclin $\mathrm{G}$ promotes cell growth: p53 downstream effectors cyclin $\mathrm{G}$ and Gadd45 exert different effects on cisplatin chemosensitivity. Exp Cell Res 230: 61-68, 1997. 
65. Kwon SH, Park JC, Ramachandran S, Cha SD, Kwon KY, Park JK, Park JW, Bae I and Cho CH: Loss of cyclin G1 expression in human uterine leiomyoma induces apoptosis. Reprod Sci 15: 400-410, 2008

66. Greenman C, Stephens P, Smith R, Dalgliesh GL, Hunter C, Bignell G, Davies H, Teague J, Butler A, Stevens C, Edkins S, et al: Patterns of somatic mutation in human cancer genomes. Nature 446: 153-158, 2007.

67. Wood LD, Parsons W, Jones S, Lin J, Sjoblom T, Leary RJ, Shen D, Boca SM, Barber T, Ptak J, Silliman N, et al: The genomic landscapes of human breast and colorectal cancers. Science 318: 1108-1113, 2007

68. Ding L, Getz G, Wheeler DA, Mardis ER, McLellan MD, Cibulskis K, Sougnez C, Greulich H, Muzny DM, Margan MB, Fulton L, et al: Somatic mutations affect key pathways in lung adenocarcinoma. Nature 455: 1069-1075, 2008.

69. Ley TJ, Mardis ER, Ding L, Fulton B, McLellan MD, Chen K, Cooling D, Dunford-Shore BH, McGrath S, Hickenbotham M, Cook L, et al: DNA sequencing of a cytogenetically normal acute myeloid leukaemia genome. Nature 456: 66-72, 2008.

70. Karapetis CS, Khambata-Ford S, Jonker DJ, O'Callaghan CJ, Tu D, Tebbutt NC, Simes RJ, Chalchal H, Shapiro JD, Robitaille S, Price TJ, et al: K-ras mutations and benefit from cetuximab in advanced colorectal cancer. N Engl J Med 359: 1757-1765, 2008.

71. Schneider BP, Wang M, Radovich M, Siedge GW, Badve S, Thor A, Flockhart DA, Hancock B, Davidson N, Gralow J, Dickler M, et al: Association of vascular endothelial growth factor and vascular endothelial growth factor receptor-2 genetic polymorphisms with outcome in a trial of paclitaxel compared with paclitaxel and bevacizumab in advanced breast cancer. J Clin Oncol 26: 4672-4678, 2008.

72. Raponi M, Winkler and Dracopoli NC: KRAS mutations predict response to EGFR inhibitors. Curr Opin Pharmacol 8: 413-418, 2008.

73. Burris III H and Rocha-Lima C: New therapeutic directions for advanced pancreatic cancer: Targeting the epidermal growth factor and vascular endothelial growth factor pathways. Oncologist 3 : 289-298, 2008

74. Nieto J, Grossbard ML and Kozuch P: Metastatic pancreatic cancer 2008: is the glass less empty? Oncologist 13: 562-576, 2008.

75. Scappaticci FA, Skillings JR, Holden SN, Gerber HP, Miller K, Kabbinavar F, Bergsland E, Ngai J, Holmgren E, Wang J and Hurwitz H: Arterial thromboembolic events in patients with metastatic carcinoma treated with chemotherapy and bevacizumab. J Natl Cancer Inst 99: 1232-1239, 2007.

76. Roodhart JM, Langenberg MH, Witteveen E and Voest EE: The molecular basis of class side effects due to treatment with inhibitors of the VEGF/FEGFR pathway. Curr Clin Pharmacol 3: $132-143,2008$
77. Nalluri SR, Chu D, Keresztes R, Zhu X and Wu S: Risk of venous thromboembolism with the angiogenesis inhibitor bevacizumab in cancer patients: A meta-analysis. JAMA 300: 2277-2285, 2008.

78. Lenz H-J, Anderson WF, Hall FL and Gordon EM: Clinical Protocol: tumor site specific phase I evaluation of safety and efficacy of hepatic arterial infusion of a matrix-targeted retroviral vector bearing a dominant negative cyclin G1 construct as intervention for colorectal carcinoma metastatic to liver. Hum Gene Ther 13: 1515-1537, 2002.

79. Morse M: Technology evaluation: Rexin-G, Epeius Biotechnologies. Curr Opin Mol Ther 7: 164-169, 2005.

80. Galanis E, Carlson SK, Foster NR, Lowe V, Quevedo F, McWilliams RR, Grothey A, Jatoi A, Alberts SR and Rubin J: Phase I trial of a pathotropic retroviral vector expressing a cytocidal cyclin G1 construct (Rexin-G) in patients with advanced pancreatic cancer. Mol Ther 16: 979-984, 2008.

81. Chawla SP, Chua VS, Mohan V, Alzwahereh K, Kalra A, Quon D, Gordon EM and Hall FL: Phase I/II study of targeted gene delivery in vivo - intravenous infusions of Rexin-G - demonstrates significant biologic activity by FDG-PET-CT without toxicity in patients with progressive chemo-resistant sarcoma, breast cancer and pancreatic cancer. J Clin Oncol 26: abs. 14509, 2008.

82. Chua VS, Chawla SP, Kalra A, Quon D, Beltran K, Saralou A, Kita K, Gordon EM and Hall FL: Phase I/II study of targeted gene delivery in vivo - intravenous infusion of pathotropic nanoparticles bearing a cytocidal cyclin G1 gene (Rexin-G) - demonsrtrates anti-tumor activity in chemo-resistant metastatic bone and soft tissue sarcoma. The Cardiothoracic Surgery Network and CTOS 14th Annual Meeting, London, UK, 2008.

83. Chawla SP, Chua VS, Kalra A, Quon D, Beltran K, Saralou A Kita K, Gordon EM and Hall FL: Phase II study of pathotropic nanoparticles bearing a cytocidal cyclin G1 construct (Rexin-G) reveals significant anti-tumor activity with no toxicity in chemo-resistant metastatic osteosarcoma. The Cardiothoracic Surgery Network and CTOS 14th Annual Meeting, London, UK, 2008.

84. Cornelio GH, Lorenzo CC, Lopez FF, Gordon EM and Hall FL: Phase I study of sequential targeted gene delivery: intravenous infusions of Rexin-G followed by Reximmune-C induce tumor necrosis and recruitment of tumor infiltrating lymphocytes in cancerous lesions. J Clin Oncol 26: abs. 3077, 2008.

85. Hall FL and Gordon EM: Method of delivering therapeutic agents to site of tissue injury. University of Southern California/ Epeius Biotechnologies Corp. US Patent 7347998, 2008.

86. Hall FL, Gordon EM, Anderson WF and Starnes VA: Modified proteins which bind to extracellular matrix components. University of Southern California/Epeius Biotechnologies Corp. EP0973538, 2008. 